\title{
Mobile Technologies: Tools for Organizational Learning and Management in Schools
}

\section{iPrincipals: Analyzing the Use of iPads by School Administrators}

\author{
Joe Winslow $^{1}$, Jeremy Dickerson ${ }^{1}$, Cheng-Yuan Lee ${ }^{1} \&$ Gregory Geer $^{1}$ \\ ${ }^{1}$ Coastal Carolina University, Conway, SC, USA \\ Correspondence: Joe Winslow, Spadoni College of Education, Coastal Carolina University, USA. Tel: \\ 843-349-2613. E-mail: jwinslow@coastal.edu
}

Received: April 1, 2012 Accepted: April 16, 2012 Online Published: July 4, 2012

doi:10.5539/ies.v5n4p188 URL: http://dx.doi.org/10.5539/ies.v5n4p188

\begin{abstract}
This paper reports findings from an evaluation of a district-wide initiative deploying iPads to school administrators (principals) to improve workflow efficiencies and promote technology leadership self-efficacy. The findings indicate that iPad utilization not only facilitated administrative tasks (memos, calendars, etc.), but also improved specific complex administrator responsibilities such as teacher evaluations. School administrators perceived that their use of iPads improved their professional image, augmented their ability to lead in a technologically advanced workplace, and generated a significant return on the district's financial investment. Data, analysis, reflections, connections to teacher education, technology in schools, principal preparation and future research directions are presented.
\end{abstract}

Keywords: iPad, principal, leadership, self-efficacy

\section{Introduction}

Effective technology utilization modeled by school administrators both facilitates and unifies the efforts of students and teachers to create a digital-age learning culture within a school. A review of the International Society for Technology in Education, National Educational Technology Standards for Students (ISTE, 2007), Teachers (ISTE, 2008) and Administrators (ISTE, 2009) supports and promotes this concept. Although technology integration for school administrators has been addressed in the literature, the breadth and depth of previous inquiry is much less than the research on technology integration for K-12 students and teachers. Studies have suggested technological literacy as a predictor for successful school leaders, but these investigations have generally focused on either data analytics or office productivity software. In contrast, this study examines the impact of a specific technology, the Apple iPad tablet computer, within the context of a district-wide leadership initiative to explore its utility as a tool for school administrators and to determine the value gained from such a large technology investment. The findings also inform university faculty, providing insight into the effects of technology innovation diffusion on school administration, and adding authenticity to the learning experiences integrated into related coursework.

\section{Related Literature}

Knezek (2010) states that integrating technology throughout a school system predicates significant systemic school reform. The principal plays a vital role in any successful, high-quality school (Darling-Hammond, LaPointe, Meyerson, Orr, \& Cohen, 2007; EdSource, 2008; Knapp, Copeland, \& Talbot). The role of the principal in both the leadership and management of schools is undeniably important, even if its degree of influence is debated (Murphy, 1988). There have been numerous studies and discussions on how principals' beliefs towards using technology can influence the utilization and infusion of information technologies in their schools (Otto \& Albion, 2002). Some contend that the principal will not be seen as an instructional leader without effectively managing the school environment, allowing teachers and others to concentrate on effective instruction (Moorthy, 1992). The work of the school principal is thus filled with complex issues that demand specialized knowledge and skills, such as the efficient use of time and attention to detail necessary to prioritize 
competing tasks that support school functions (Horng, Klasik, \& Loeb, 2009). As a result, a central question of this paper asks if iPad tablet computers can improve a principal's ability to perform school-based tasks.

The rationale for the purchase of iPad computers by the school district in this study was based on the supposition that they would enhance administrator productivity, improve school functioning and promote a technology-rich school climate. Stronge (1988) suggests that efforts to improve principal efficiency are warranted. This research is reinforced by others who cite a lack of time to execute instructional improvement due to paperwork and the general and increasing expectations and tasks of the principal (Flath, 1989; Fullan, 1991). Wade (2001) proposes that computer technology can enhance the principal's performance by reducing workloads and freeing up time for instructional and other administrative tasks. Dawson and Rakes (2003) show a correlation between the amount of technology training the principal has received and the integration of technology usage in the school. Research on hands-on technology utilization by school administrators has often focused on office applications, such as email, word processing, presentations, and calendars, or on managerial topics, such as budgeting, enrolment, or scheduling. These areas represent only a small portion of the performance indicators targeted in the NETS-A standards. Today's principals should model more sophisticated integration techniques if they are to succeed in modern technology-enhanced schools.

Similar to leaders and mangers in other fields, principals must use technology to manage and analyze large amounts of data. With the advent of state and national accountability mandates, the collection, analysis, and transmission of student achievement data has become essential. Both quantitative and qualitative student performance data are used to improve instructional practices, plan curricula, and provide assessment of instruction and student learning (Elias, Cafolla, \& Schoon, 2000). These practices demand the utilization of student information databases, managed through gateway systems such as SASI or DATATEL, and analyzed with third party tools, such as Excel or SPSS (Cafolla \& Schoon, 2001). Davies (2010) suggests that a critical task for the principal is to formulate, communicate and operationalize the school's vision by being a technology role model. This notion is echoed in Standards One and Two of the NETS-A, which states that principals must facilitate a vision for technology and model and promote the frequent and effective use of technology for learning (ISTE, 2009). An educational leader should also ensure the alignment of school technology goals with district technology goals (Hall, 2008). Maurer and Davidson (1998) suggest that the model utilization of presentation and email tools by principals helps facilitate technology integration by faculty, staff, and students. Likewise, other researchers have noted the positive impact of technology use by administrators on teachers' integration of technology into instruction (Coley, Cradler, \& Foley, 1997; Hannay \& Ross, 1997; Wiebe, 1999). Thus, the general consensus is that if the principal utilizes technology meaningfully, faculty, staff, and students are more likely to use these tools as well.

In recent years, there has been an increase in the use of handheld computers called Personal Digital Assistants (PDA) by school administrators. Although the reported levels of adoption of these tools are mixed, with Dianis (2003) reporting that $72 \%$ of principals were using PDAs while Felton's 2006 study found approximately 25\%, it is significant to note that the school districts identified mixed or less than positive experiences with integrating these handheld tools meaningfully into school administrator tasks, citing technical reliability, difficulty of use, and training as confounding issues. Currently, there are studies being conducted to evaluate the use of iPads in education (McCrea, 2011). The aforementioned literature provides a useful framework for the study described in this paper, particularly in the identification of potential workflow variables relevant to the utilization of iPad computers by school principals.

\section{Methods}

The research questions in this study evolved from collaborative discussions with school district leaders interested in evaluating their iPad deployment project. The research questions are:

1) What professional school administrator tasks are improved by using iPads?

2) Does iPad utilization increase administrator perceptions of technology leadership self-efficacy?

3) Given the current budget climate, do school administrators perceive iPads as worthwhile investments?

The researchers collaborated with district leaders to design an anonymous electronic survey sent to every school principal $(\mathrm{N}=54)$ in the district. The survey included three categories of items -- general and contextual demographics, workflow analytics, and perceptions of impact. The majority of items targeted how participants used iPads to complete various job duties, how much training they received, as well as estimates of return on investment and impact on self-efficacy as a school administrator. All data were held anonymously by the 
researchers and analyzed as a homogenized set without special selectivity or stratification to any individual participant or group of participants.

\section{Findings}

A total of $37(\mathrm{~N}=37)$ active principals completed the survey, yielding a response rate of $69 \%$. With this $\mathrm{N}(>30)$ and high response rate, the researchers concluded that the data set was suitable for the descriptive analysis that follows.

Table 1. Demographic Data

\begin{tabular}{ll}
\hline Variable & Average (N= 37) \\
\hline Age & 50 \\
Years in Education & 27 \\
Experience as Principal (Years) & 9.5 \\
School Size & 825 \\
Number of Employees Supervising & 89 \\
\hline
\end{tabular}

Table 2. Contextual Responses

Responses

Total Percentage

100.0

What is the classification of your school?

Elementary (PK-5)

17

46.0

Middle (6-8)

9

24.3

High (9-12)

11

29.7

What is your highest level of graduate training?

Masters

$10 \quad 27.0$

Masters +

20

54.0

Doctorate

7

19.0

Prior to receiving an iPad from the district, did you already own or regularly use an iPad?

No

Yes

Which mobile phone platform do you use regularly?

Blackberry

Other

Windows

iPhone

Droid 
Table 3. Improvement in Administrative Tasks as a result of iPad Utilization

\begin{tabular}{|c|c|c|c|c|c|}
\hline \multicolumn{5}{|c|}{$\begin{array}{l}\text { Responsibilities } \\
\text { Participants: Total (Percentage) }\end{array}$} & \multirow{3}{*}{$\begin{array}{l}\text { Selections by } \\
\text { Significant } \\
\text { Improvemen }\end{array}$} \\
\hline & No & Not & No & Some & \\
\hline & Response & Applicable & Improvement & Improvement & \\
\hline $\begin{array}{l}\text { Walkthrough teacher } \\
\text { evaluations }\end{array}$ & $0(0.0)$ & $0(0.0)$ & $0(0.0)$ & $4(10.8)$ & 33(89.2) \\
\hline Managing time/calendar & $0(0.0)$ & $0(0.0)$ & $1(2.7)$ & $13(35.1)$ & $23(62.2)$ \\
\hline Taking notes & $0(0.0)$ & $0(0.0)$ & $1(2.7)$ & $16(43.2)$ & $20(54.1)$ \\
\hline Writing memos & $0(0.0)$ & $1(2.7)$ & $3(8.1)$ & $15(40.5)$ & 18(48.6) \\
\hline $\begin{array}{l}\text { Formal teacher } \\
\text { evaluations }\end{array}$ & $0(0.0)$ & $1(2.7)$ & $7(18.9)$ & 11(29.7) & 18(48.6) \\
\hline Curriculum management & $0(0.0)$ & $0(0.0)$ & $2(5.4)$ & 19(51.4) & $16(43.2)$ \\
\hline Sharing documents & $0(0.0)$ & $0(0.0)$ & $8(21.6)$ & $18(48.6)$ & 11(29.7) \\
\hline Student data analysis & $1(2.7)$ & $0(0.0)$ & $10(27.0)$ & $15(40.5)$ & 11(29.7) \\
\hline Event planning & $1(2.7)$ & $0(0.0)$ & 11(29.7) & $14(37.8)$ & 11(29.7) \\
\hline Student supervision & $1(2.7)$ & $3(8.1)$ & $9(24.3)$ & $14(37.8)$ & $10(27.0)$ \\
\hline Special education & $0(0.0)$ & $1(2.7)$ & $14(37.8)$ & $13(35.1)$ & $9(24.3)$ \\
\hline $\begin{array}{l}\text { Professional } \\
\text { development }\end{array}$ & $0(0.0)$ & $0(0.0)$ & $7(18.9)$ & $22(59.5)$ & $8(21.6)$ \\
\hline Support staff supervision & $1(2.7)$ & $2(5.4)$ & $13(35.1)$ & 14(37.8) & $7(18.9)$ \\
\hline Transportation & $1(2.7)$ & $9(24.3)$ & 19(51.4) & $4(10.8)$ & $4(10.8)$ \\
\hline Inventory & $0(0.0)$ & $7(18.9)$ & $23(62.2)$ & $3(8.1)$ & $4(10.8)$ \\
\hline Parent conferences & $1(2.7)$ & $6(16.2)$ & 11(29.7) & $16(43.2)$ & $3(8.1)$ \\
\hline Student discipline & $2(5.4)$ & $3(8.1)$ & 18(48.6) & $12(32.4)$ & $2(5.4)$ \\
\hline Budgeting & $0(0.0)$ & $2(5.4)$ & $22(59.5)$ & 11(29.7) & $2(5.4)$ \\
\hline Textbook adoption & $0(0.0)$ & $10(27.0)$ & $22(59.5)$ & $4(10.8)$ & $1(2.7)$ \\
\hline Grants & $0(0.0)$ & $5(13.5)$ & $25(67.6)$ & 7(18.9) & $0(0.0)$ \\
\hline
\end{tabular}

Table 4. Perceptions of Impact

\begin{tabular}{|c|c|c|c|c|}
\hline \multicolumn{5}{|l|}{$\begin{array}{l}\text { Questions } \\
\text { Total (Percentage) }\end{array}$} \\
\hline & $\begin{array}{l}\text { Strongly } \\
\text { Disagree }\end{array}$ & Disagree & Agree & $\begin{array}{l}\text { Strongly } \\
\text { Agree }\end{array}$ \\
\hline $\begin{array}{l}\text { The iPad significantly enhances my ability to be an } \\
\text { effective administrator. }\end{array}$ & 7(18.9) & $2(5.4)$ & 13(35.1) & $15(40.5)$ \\
\hline $\begin{array}{l}\text { Using the iPad improves my perception as a } \\
\text { technologically competent school administrator. }\end{array}$ & $4(10.8)$ & $1(2.7)$ & $19(51.4)$ & 13(35.1) \\
\hline $\begin{array}{l}\text { Purchasing iPads for every principal is a } \\
\text { worthwhile investment with measurable } \\
\text { productivity gains. }\end{array}$ & $1(2.7)$ & $0(0.0)$ & $12(32.4)$ & 24(64.9) \\
\hline $\begin{array}{l}\text { I feel confident about my technical ability to use my } \\
\text { iPad for professional needs. }\end{array}$ & $1(2.7)$ & $4(11.1)$ & 23(63.9) & $8(22.2)$ \\
\hline
\end{tabular}




\section{Discussion}

\subsection{Demographics and Context}

The data presented in Tables 1 and 2 allow the researchers to make several inferences necessary for answering the research questions of this study. Generally, the participants of this study are veteran educational professionals with high levels of experience (27 years of educational experience and 9.5 years of experience as a school administrator) and strong academic credentials (73\% having either a Master's Degree with additional credits or a Doctoral Degree). With an average school size of over 800 students and supervised employees averaging 89, these principals lead schools of significant size relative to most districts in the southeastern region of the United States. Forty-six percent of these schools are elementary schools, with the remaining $54 \%$ split between middle and high schools. These demographics qualify the group as experienced, middle-aged educational leaders in mid-sized schools, and suggest that their perspectives could generalize to larger populations of school administrators of similar age and experience.

Table 2 also presents data about the entry skill levels of the participants prior to the project, specifically their ownership and experiences using iPads or mobile phones. This information is important because the presence or absence of prior knowledge and experiences with similar technologies or devices can greatly influence the use, perceptions and learning process. These data show that only $8.1 \%$ of participants personally owned or used an iPhone and $10.8 \%$ personally owned or used an iPad before the project, which suggests that in general, prior knowledge was not a contaminating factor undermining the validity of other data. It also suggests that the learning process could have been steep and rigorous for some participants, possibly influencing reported perceptions (negatively).

\subsection{Workflow Analytics and Administrator Perceptions}

As the data in Table 3 demonstrate, participating administrators identified numerous professional task workflows that were improved by the use of iPads. It is particularly interesting to note that all $37(100 \%)$ of responding principals agreed that iPad utilization added some improvement or significant improvement to the walkthrough teacher evaluation process. Also ranking very high on this list is time management/calendering (97.3\%), note taking (97.3\%) and memo writing (89.2\%). The researchers felt that there were several trends worthy of discussion from these data. First, it was not surprising that calendar management, memo writing, and note taking were high scoring items, as iPads are purpose-built devices that bundle "apps" specifically written to leverage the touchscreen interfaces and reduced ergonomic footprints inherent to tablet devices, a convenience for professionals with dynamic and mobile workflows that demand constant document and communication productivity. Second, $86 \%$ of participants reported that they felt confident in their technical abilities to use the iPad, which is especially interesting when one considers that the vast majority reported receiving minimal or no training and few (3) had any prior experiences. Third, and perhaps this finding is the most compelling - participants showed unanimous support for using the iPad in the "walkthrough" teacher evaluation process, which required principals to observe and rate teachers in real-time with a network-based application that recorded numerical scores, text narratives and digital videos. The significance of such profound agreement on this specific professional workflow is that it logically invites further inquiry, particularly into the training and policies surrounding the process as implemented in this school district. Finally, it is worth noting that the majority of responding principals (75.6\%), as evidenced in Table 4, reported that they either agreed or strongly agreed that the iPad significantly improves their effectiveness as a school administrator. Additional inquiry will be necessary to determine whether this agreement is predicated on the improvement of the walkthrough process alone, or on a more global perception that iPad utilization positively impacted a combination of professional administrative task workflows.

The second research question asked if iPad utilization helps school administrators increase their self-efficacy as school technology leaders. The data in Table 4 show that $86.5 \%$ of participants either agreed or strongly agreed that the use of iPads helped improve their image as someone who is technologically competent. This is an important finding because technology use by a school administrator has been identified as a critical motivational factor for stakeholders such as students and teachers to believe that technology integration is systemic and meaningful throughout all levels of a school (Garland, 2009; Gosmire \& Grady, 2007). The importance of such modeling is also underscored by the NETS-A Standard One, which emphasizes the significance of visionary leadership that implements "comprehensive integration of technology to promote excellence and support transformation throughout the organization” (ISTE, 2009).

The third research question targets administrator perceptions of the potential return on investment of district funds - especially within the context of a severely reduced budget climate. As the data in Table 4 demonstrate, 
the vast majority (97\%) of participants believe that iPads were a worthwhile investment and provided measurable productivity gains in school administrator workflows. It is important to note here that the iPads in this project were limited to professional use only; the district technology office installed auditing applications to monitor for personal use, with strict consequences for detected violations. None were reported, and so the researchers feel reasonably confident that the risk of positive bias was significantly diminished. These data are also significant because they report the feedback of school administrators on a budgetary item during a time of extreme fiscal hardship. School principals understand the diminished economic state currently challenging most districts and would likely not support exploratory spending on technology without tangible positive impacts.

\section{Conclusions and Future Research}

The purchase and deployment of iPads for all school administrators within a district was a decision that required both calculated risk taking and a commitment to technology innovation. The data reported in this study suggest that iPads can help school administrators not only facilitate mundane administrative tasks (memos, calendars, etc.), but can also improve specific administrator workflows, such as teacher evaluations, in a dramatic manner. The data also suggest that school administrators perceive that the use of iPads improves their professional image and augments their ability to lead in a technologically advanced workplace. Given the economic conditions of school systems all over the United States, it is vital to make wise technology budget decisions that provide measurable returns on investment. The data here support the notion that this was not only a positively perceived investment, but an investment with clearly identified where administrator workflow improvements.

The researchers believe that future inquiry should examine the walkthrough teacher evaluation process more closely to measure exactly how the iPad and/or other tablet computing devices can influence administrator workflow and subsequently how teachers benefit from such utilization. The researchers have collected anecdotal data that suggest worthwhile follow-up studies might target variables such as evaluation feedback logistics, particularly the expediency of real-time reporting, application usability and technical design, as well as the impact on classroom instruction, teacher reflection and student achievement.

\subsection{Implications for Teaching Pre-service and In-service Teachers}

As new devices compete to reshape the mobile landscape of the near future, the notion of principals using iPads for school administration heralds a prodigal change in the way future educators will be trained to use instructional technology. At the necessity of preparing students to live and work in the $21^{\text {st }}$ Century as well as the compliance of accreditation organizations, technology leadership is now an expectation of school administrators. When this trend is examined within the context of ongoing paradigm changes in technology and education, it is paramount that teacher education programs prepare candidates to master emerging new technological competencies. These could include, for example, using mobile tablet devices to:

- $\quad$ access and integrate digital content during classroom instruction;

- manage the exchange of student performance data to and from server-side infrastructure, such as learning management systems;

- leverage gesture-based interactions, such as swiping and multi-touch, in meaningful ways that engage students differently from mouse clicking.

Clearly, now more than ever, students, teachers, administrators, school district leaders and teacher education programs must work together to prepare students to live and work in a technological society. Studies such as the one discussed in this paper help illustrate how educators can help close the gaps in school technology use by all constituents and promote a more holistic technology environment in schools. As tools like the iPad and its tablet PC successors compete for future dominance in personal consumer markets, exploration should continue in their potential utility in the professional workplace, particularly for applications that promote student achievement, teacher success and school improvement.

\section{References}

Cafolla, R., \& Schoon, P. (2001). Implementing an instructional management system: Final report. In J. R. Tollett (Ed.), Proceedings of the Twelfth Society for Information Technology \& Teacher Education International Conference (pp. 16-19). Orlando, FL, March 5-10, 2001.

Coley, R. J., Cradler, J., \& Engle, P. K. (1997). Computers and classrooms: The status of technology in U.S. schools. Princeton, NJ: Policy Information Center, Educational Testing Service 
Darling-Hammond, L., Lapointe, M., Meyerson, D., Orr, M. T., \& Cohen, C. (2007). Preparing school leaders for a changing world: Lessons from exemplary leadership development programs. Stanford, CA: Stanford University

Davies, P. M. (2010). On school educational technology leadership. Management in education, 24, 55-61. http://dx.doi.org/10.1177/0892020610363089

Dawson, C., \& Rakes, G. (2003). The influence of principals' technology training on the integration of technology into schools. Journal of research on Technology in education, 36(1). 29-49.

Dianis, L. (2003, April). PDA use mashup. District Administrator, 39(4), p.56.

EdSource. (2008). Guiding the growth of California's school leaders. Leadership. (January/February),18-21.

Elias, J., Cafolla, R., \& Schoon, P. (2000). The selection of an instructional management system. Journal of Technology and Teacher Education, 8(2), 123-131.

Felton, F. S. (2006). The use of computers by elementary school principals. Retrieved from http://scholar.lib.vt.edu/theses/available/etd-04242006-144854/unrestricted/FFelton04202006.pdf

Flath, B. (1989). The principal as instructional leader. ATA Magazines, 69(3), 19-22, 47-49.

Fullan, M. (1991). The new meaning of educational change. New York: Teachers College Press

Garland, V. (2009). Emerging technology trends and ethical practices for the school principal. Journal of Educational Technology Systems, 38(1), 39-50. http://dx.doi.org/10.2190/ET.38.1.e

Gosmire, D., \& Grady, M. (2007). Principal as Technology Leader. Principal Leadership, 7(6) 16-21.

Hall, D. (2008). The technology director's guide to leadership. Washington, DC: ISTE.

Hannay, L., \& Ross, J. (1997). Initiating secondary school reform: The dynamic relationship between restructuring, reculturing and retiming. Education Administration Quarterly, 33, 576-603. http://dx.doi.org/10.1177/0013161X970331004

Horng. E. L., Klasik, D., \& Loeb, S. (2009). Principal time-use and school effectiveness. Working Paper 34. Washington, DC: National Center for Analysis of Longitudinal Data in Educational Research.

ISTE (2007). NETS for Students. Retrieved from http://www.iste.org/standards/nets-for-students.aspx (February $3,2011)$

ISTE (2008). NETS for Teachers. Retrieved from http://www.iste.org/standards/nets-for-teachers.aspx (February 3, 2011)

ISTE (2009). NETS for Administrators. Retrieved from http://www.iste.org/standards/nets-for-administrators.aspx (February 3, 2011)

Knapp, M. S., Copland \& M. A., Talbert, J. E. (2003). Leading for learning: Reflective tools for school and district leaders (research report). Seattle, WA: Center for the Study of Teaching and Policy.

Knezek, D. (2010). ISTE NETS for Administrators. Retrieved from http://www.iste.org/standards/nets-for-administrators.aspx (February 3, 2011)

Maurer, M. M., \& Davidson, G. M. (1998). Leadership in instructional technology. Columbus, OH: Merrill

McCrea, B. (2011). Evaluating the iPad for Education. Campus Technology, February 2, 2011, Retrieved from http://campustechnology.com/articles/2011/02/02/evaluating-the-ipad-for-education.aspx (February 16, 2011)

Moorthy, D. (1992). The Canadian principal of the '90's: Manager or instructional leader? Or both? Education Canada, 32(2), 8-11.

Murphy, J. (1988). Methodological, measurement, and conceptual problems in the study of school leadership. Educational Evaluation and Policy analysis, 4(4), 290-310.

Otto, T., \& Albion, P. (2002). Understanding the role of school leaders in realizing the potential of ICTs in education. In D. Willis, J. Price, N. Davis (Eds.), Proceedings of Society for Information Technology \& Teacher Education International Conference 2002 (pp. 506-510). Chesapeake, VA: AACE.

Stronge, J. H. (1988). A position in transition? Principal, 67(5), 32-33.

Wade, H. H. (2001). Data inquiry and analysis for educational reform. Clearinghouse on Educational Policy and Management (ERIC Digest 153). 
Wiebe, E. N. (1999). Integration of electronic mail into schools. Journal of Educational Computing Research, 21(1), 55-73. http://dx.doi.org/10.2190/5TXG-7VC0-KHW5-5AN9 